\title{
The problem of future contingents: scoping out a solution
}

\author{
Patrick Todd ${ }^{1}$ \\ Received: 3 April 2018 / Accepted: 22 September 2018 / Published online: 9 October 2018 \\ (c) The Author(s) 2018
}

\begin{abstract}
Various philosophers have long since been attracted to the doctrine that future contingent propositions systematically fail to be true-what is sometimes called the doctrine of the open future. However, open futurists have always struggled to articulate how their view interacts with standard principles of classical logic-most notably, with the Law of Excluded Middle (LEM). For consider the following two claims: (a) Trump will be impeached tomorrow; (b) Trump will not be impeached tomorrow. According to the kind of open futurist at issue, both of these claims may well fail to be true. According to many, however, the disjunction of these claims can be represented as $p$ $\vee \sim p$ - that is, as an instance of LEM. In this essay, however, I wish to defend the view that the disjunction these claims cannot be represented as an instance of $p \vee \sim p$. And this is for the following reason: the latter claim is not, in fact, the strict negation of the former. More particularly, there is an important semantic distinction between the strict negation of the first claim [ (Trump will be impeached tomorrow) $]$ and the latter claim (Trump will not be impeached tomorrow). However, the viability of this approach has been denied by Thomason (Theoria 36:264-281, 1970), and more recently by MacFarlane (Assessment sensitivity: relative truth and its applications, Oxford University Press, Oxford, 2013) and Cariani and Santorio (Mind 127:129-165. doi: https://doi.or $\mathrm{g} / 10.1093 / \mathrm{mind} / \mathrm{fzw} 004,2017)$, the latter of whom call the denial of the given semantic distinction "scopelessness". According to these authors, that is, will is "scopeless" with respect to negation; whereas there is perhaps a syntactic distinction between ' $\sim$ Will $p$ ' and 'Will $\sim p$ ', there is no corresponding semantic distinction. And if this is so, the approach in question fails. In this paper, then, I criticize the claim that will is "scopeless" with respect to negation. I argue that will is a so-called "neg-raising" predicate-and that, in this light, we can see that the requisite scope distinctions aren't missing, but are simply being masked. The result: a under-appreciated solution to the problem of future contingents that sees (a) and (b) as contraries, not contradictories.
\end{abstract}

Keywords Future contingents - The open future - Law of Excluded Middle · A.N. Prior $\cdot$ Bivalence $\cdot$ Neg-raising

Extended author information available on the last page of the article 
Various philosophers have long since been attracted to the doctrine that future contingent propositions (roughly, propositions about undetermined aspects of the future) systematically fail to be true-what is sometimes called the doctrine of the open future. However, open futurists, in this sense of the term, have always struggled to articulate how their view interacts with standard principles of classical logic-most notably, with the Law of Excluded Middle (LEM). For consider the following two claims:

There will be a sea-battle tomorrow

There will not be a sea-battle tomorrow

According to the kind of open futurist at issue, both of these claims may well fail to be true. According to many, however, the disjunction of these claims can be represented as $p \vee \sim p$-that is, as an instance of LEM. And if this is so, the open futurist is plainly in a difficult position. She must either deny LEM outright, or instead maintain that a disjunction can be true without either of its disjuncts being true. And whereas open futurists have defended both such options with considerable care and ingenuity, both are also faced with substantial costs. ${ }^{1}$

In this essay, however, I wish to explore a different option-an option that has been articulated and defended by at least one of the leading lights of tense-logic in the 20th century (A.N. Prior) but is nevertheless often bypassed and even ignored. This is the position that, in fact, the disjunction of the above two claims cannot be represented as an instance of $p \vee \sim p$. And this is for the following reason: the latter claim is not, in fact, the strict negation of the former. More particularly, there is an important semantic distinction between the strict negation of the first claim $[\sim$ (There will be a sea-battle tomorrow)] and the latter claim (There will not be a sea-battle tomorrow). And LEM, of course, is concerned with strict negations. ${ }^{2}$ If this semantic distinction can be maintained, the open futurist's prospects concerning LEM appear much more hopeful. For starters: she can maintain that neither of the above claims is true, but that this, in itself, tells us nothing about LEM-because the disjunction of these claims is not an instance of LEM. More to the point: she can maintain that when we do have the strict negation of the first claim, we have a claim that is just plain true, even if the future is "open". If the future is open regarding sea-battles tomorrow, then currently it is not the case that there will be such a sea-battle tomorrow. But this isn't to say that there won't be a sea-battle tomorrow. Accordingly, the open futurist can maintain that the real instance of LEM is just plain true. Problem solved.

Or so it seems. Again, the possibility of this approach is more often ignored than it is denied. But it is sometimes denied. In particular, it has been denied by Thomason (1970), and more recently by MacFarlane (2013) and Cariani and Santorio (2017), the latter of whom call the denial of the given semantic distinction "scopelessness". According to these authors, that is, will is "scopeless" with respect to negation; for instance, whereas there is perhaps a syntactic distinction between 'It is not the case that it will be tomorrow that there is a sea battle' and 'It will be the case tomorrow that it is not the case that there is a sea battle', there is no corresponding semantic

\footnotetext{
1 For the former approach, see Lukasiewicz (1920); for the latter, see esp. Thomason (1970).

2 For differing defenses of this position, see Prior (1957: pp. 95-96, 1967: pp. 128-129), Hartshorne (1965), Bourne (2006): p. 91, Rhoda (2007), Todd (2016), and Hess (2017).
} 
distinction-that is, no corresponding difference in meaning. And if this is so, the approach in question fails.

In this paper, however, I defend the unorthodox position that the above two claims are classical contraries (both can be false, but not both true) - and I thereby criticize the claim that will is "scopeless" with respect to negation. The central theme underlying my position is this: philosophers (and semanticists) are often mistaking semantic competence with will with what is in fact semantic competence with will together with an implicit metaphysical model of the future. However, once this model is denied, the judgments undergirding scopelessness lose their motivation and justification. Thus, in this paper, I develop a sort of "error-theory" for certain ordinary semantic intuitions about will. Adopting Prior's (1957: pp. 11-12) metric tense operator 'Fnp' as shorthand for 'It will be in $\mathrm{n}$ units of time hence that $p$ ', I contend that the dominant metaphysical model of the future implicit in ordinary, unreflective discourse renders it the case that $\sim \mathbf{F n} p$ implies $\mathbf{F n} \sim p$. Accordingly, when this model is operative in the background of the discourse, it is, naturally, unimportant to distinguish between $\sim \mathbf{F n} p$ and $\mathbf{F n} \sim p$, for the model makes it the case that whenever we have the former, we have the latter. However, once one firmly denies the given model of the future, as does the open futurist, all bets are off: we can see that $\sim \mathbf{F n} p$ does not mean $\mathbf{F n} \sim p$. The distinction, to be sure, is a philosophers' distinction. But it is a distinction nonetheless. And when it comes to articulating the philosophical theory of the open future, this is what matters.

I develop this point by defending the claim that will is so-called neg-raising predicate. "Neg-raising" refers to the widespread semantic phenomenon whereby what is in fact semantically wide-scope negation gets treated, in context, as if it belonged to the relevant embedded clause. For instance, I don't think that Trump is a good president strongly tends to implicate I think that Trump is not a good president-despite the former not semantically entailing the latter. The phenomenon of neg-raising has generated a substantial discussion in the linguistics literature-and the present paper thus aims, in part, to make a contribution to that literature. ${ }^{3}$ However, I do not aim to make a direct contribution to providing a theory of neg-raising - a theory that would predict which predicates are neg-raising and why. Rather, my aim here is to show that, whatever its fundamental explanation, the phenomenon can also be seen to apply to will and will not. As I hope becomes clear, seeing will as a neg-raiser promises to solve what would otherwise be intractable problems in the philosophical theory of the open future.

\section{Scopelesssness}

The claim at issue is that will is "scopeless" with respect to negation. Under the heading Missing Scope Distinctions, John MacFarlane articulates the thesis by comparing two claims, and writes as follows:

\footnotetext{
3 For a start, see Horn (1978, 1989): Ch. 5, and, for the most comprehensive treatment, Collins and Postal (2014).
} 
(13) It is not the case that it will be sunny tomorrow

$\sim$ Tomorrow $S$

(14) It will be the case tomorrow that it is not sunny Tomorrow $\sim S$

It is striking, though, that although we can mark the syntactic distinction by resorting to cumbersome circumlocutions, as in (13)-(14), these variants seem like different ways of saying the same thing. (2013: p. 216)

According to MacFarlane, then, we can simply push the negation in (13) inside the scope of the "Tomorrow" (thereby getting (14)), and we can do so without any change in meaning.

Note: MacFarlane makes the claim that the requisite scope distinctions are "missing" in the context of a criticism of the so-called (by Prior) "Peircean" semantics for will, which treat will as a universal quantifier over all open causal possibilities (all open 'branches'). (These are the semantics defended in Prior 1957: pp. 95-96, 1967: pp. 128-129, and Hartshorne 1965). If 'It will be in $\mathrm{n}$ units of time hence that $p$ ' meant 'On All Branches, in $\mathrm{n}$ units of time hence, $p$ ', we would expect to see a plain scope difference between $\sim \mathbf{F n} p$ and $\mathbf{F n} \sim p$-which we don't see, according to MacFarlane. However, in what follows, I defend the given scope distinction, but not by means of a defense of the Peircean semantics for will. ${ }^{4}$

Following MacFarlane, Cariani and Santorio write:

Our second constraint [on developing a semantics for will] is that will is scopeless with respect to an important class of other linguistic items. By this we mean that changes in the relative syntactic scope between will and these other items don't make a difference to the truth conditions of will-sentences. This is a remarkable feature of will, and one that is not generally shared by modal expressions. For present purposes, it is enough to observe scopelessness with respect to negative items, as illustrated by:

(9) a. It will not rain.

b. It is not the case that it will rain.

(9)a and (9)b are truth conditionally equivalent... In short, will appears to commute freely with ordinary English negation. ... The lack of scope interactions with negation immediately yields an interesting logical constraint:

\footnotetext{
4 A further note: MacFarlane is here clearly assuming that time does not end prior to tomorrow; in other words, his claim is that (13) and (14) say the same thing, under the assumption that time does not end prior to tomorrow. Clearly, (13) and (14) may come apart, if one is assuming that time ends a few minutes from now, well before "tomorrow". If time ends in a few minutes, (13) is presumably true and (14) false. The intuitive idea, again, is that (13) and (14) are equivalent in meaning, under the assumption that time does not end prior to tomorrow. In what follows, I make the relevant parallel assumption, and ignore this complication. It is worth noting, however, that this observation does complicate MacFarlane's contention that there is no important distinction in scope between (13) and (14).
} 
Will Excluded Middle (preliminary take): 'Will $\mathrm{A} \vee$ Will $\sim \mathrm{A}$ ' is a logical truth. ${ }^{5}$ (2017: pp. 6-7)

Neither MacFarlane nor Cariani and Santorio put their points in terms of a metric tense operator; MacFarlane employs a (similar) 'tomorrow' operator, and Cariani and Santorio employ a non-metric 'will' operator. For various reasons, however, it will be convenient in what follows to employ a metric operator-and clearly whatever reasons MacFarlane and Cariani and Santorio have given above for "scopelessness" regarding 'tomorrow' and 'will' apply mutatis mutandis to 'It will be in units of time hence that...'. Thus, again, adopting 'Fn $p$ ' as shorthand for 'It will be in $\mathrm{n}$ units of time hence that $p$, the claim at issue is that there is no semantic distinction between $\sim \mathrm{Fn} p$ and $\mathbf{F} n \sim p$. According to these authors, that is, making a sharp distinction between $\sim \mathbf{F n} p$ and $\mathbf{F n} \sim p$ is approximately similar to making a sharp distinction between $(p \wedge q)$ and $(q \wedge p)$. The "order" of the negation with respect to will is as semantically irrelevant as is the "order" of the conjuncts with respect to conjunction. In this sense: will is scopeless with respect to negation.

But I deny that will is, in this sense, scopeless with respect to negation. In particular, I deny that (13) implies (14). The position I wish to defend in this paper, inter alia, is that (14) implies (13), but (13) does not imply (14). Accordingly, these claims do not have the same meaning. Now, there is a sense in which I agree with these philosophers: it is, in ordinary contexts, extremely difficult to hear any distinction between (13) and (14) - that is, between $\sim \mathbf{F n} p$ and $\mathbf{F n} \sim p$. In ordinary contexts, that is, if you deny that the future features $p$ in $\mathrm{n}$ units of time, then you affirm that that the future features $\sim p$ in $\mathrm{n}$ units of time. This is because, in ordinary contexts, it is presupposed that there exists what we might call "the future"-and so, if it doesn't feature $p$ in n units time, it instead features $\sim p$ in $\mathrm{n}$ units time. However, my contention is this. Once we move to (admittedly) non-ordinary, metaphysically-loaded contexts, in which we are explicitly considering the metaphysical model of the "open future", we can see that scopelessness breaks down. In such a context, there is, I argue, no reason to maintain that if it is not the case that the future features $p$ in $\mathrm{n}$ units time, it therefore follows that it instead features $\sim p$ in $\mathrm{n}$ units time. Of course not: there is no such thing as "the future"! Contra the above authors, then, we cannot simply push the negation in $\sim \mathrm{F} n p$ inside the scope of the "F" to achieve $\mathbf{F n} \sim p$. More particularly, the claim that you can do so requires (or perhaps just $i s$ ) a substantive theory of the future-a theory of the future that may indeed be plausible (and is certainly widespread), but a theory of the future that the open futurist, as it happens, rejects. The inference holds, if it holds at all, as a matter of metaphysics, not semantics.

\footnotetext{
5 As Cariani and Santorio recognize, if a given operator $\mathbf{S}$ is scopeless, then if the Law of Excluded Middle is a logical truth, then $\mathbf{S}$-Excluded Middle will be a logical truth, viz. ' $\mathbf{S} p \vee \mathbf{S} \sim p$ '. Assuming LEM, the claim that an operator $\mathbf{S}$ is scopeless is, therefore, equivalent to the claim that $\mathbf{S}$-Excluded Middle is a logical truth. However, it is worth noting (again) that the claim that Will Excluded Middle is a logical truth is immediately complicated by the observation that a logical truth should be true at the last moment of time-but Will Excluded Middle is not true at the last moment of time. As in the note above, I set this complicating factor aside. The argument of this paper is that the metric version of Will Excluded Middle $(\mathbf{F n} p \vee \mathbf{F n} \sim p)$ fails, even if time is assumed to continue at least $\mathrm{n}+1$ units of time hence. This is the fundamental question at issue.
} 
In order to see this result, we must begin by putting on the table three different models of the undetermined future: (1) Indeterminism with no privileged branch, (2) Indeterminism with a privileged branch, but it is indeterminate which branch that is, and (3) Indeterminism with a privileged branch. And my claim is simple: because the first model has no privileged branch, it invalidates the inference from $\sim \mathbf{F n} p$ to Fn $\sim p$. However, because the latter two models do have (albeit in different ways) a privileged branch, those models validate that inference. And the model implicit in ordinary discourse is the third model, and this is what makes it difficult to hear a distinction between the two claims. Nevertheless, the first model is perfectly metaphysically coherent — and this is the model of the "open future" I wish to defend in this paper. And my claim is that we are not in position to rule out the first model in virtue of semantic competence with will and negation.

To explain. In the context of causal indeterminism, we have various "branches" that represent causally possible (maximal) ways things might go from here, consistently with the past and the laws. (Such branches will be segments of traditional abstract possible worlds.) The open futurist, in my sense of the term, adds that no one of these branches is metaphysically privileged, in the sense that that branch is uniquely "going to be". In this sense: there is no privileged branch in the model. (There is nothing, now, that deserves the title "the actual world". 6 ) Call this model indeterminism with no privileged branch. Here it is crucial to see that this model of the "open future" is to be distinguished from a different model of the open future, viz. the model we might call indeterminism with a privileged branch, but it is indeterminate which branch that $i s$. This is the model of the "open future" presupposed by Cariani and Santorio (who are in turn inspired by Barnes and Cameron 2009); indeed, they maintain that their semantics

presupposes that there is a 'unique' actual course of history. At the same time, it might be indeterminate which possible world instantiates the actual course of history. As a result, it might be indeterminate which world will selects, and will-statements may have indeterminate truth values. (2017: p. 3)

The (certainly mysterious) idea here is that though one such branch $i s$ the privileged one, it is just indeterminate which branch that is. On the first model, however, if this is what their semantics presupposes, then their semantics presupposes something false: it isn't "indeterminate" which branch is privileged-it just that, again, there is no privileged branch in the first place. ${ }^{7}$ My aim in this paper, however, is not to compare

\footnotetext{
6 Cf. Kodaj (2013).

7 Here we encounter a question for Cariani and Santorio: why is it safe to presuppose, when giving a semantics for will, that there is a unique actual course of history? And what happens to will claims when this assumption is denied? Perhaps their idea is that everyone agrees that there is such a unique actual course of history - the disagreement just concerning whether it is determinate what it is or indeterminate what it is. But this is false: certainly one standard way to express "openness" is not to say (to employ some terminology I introduce momentarily) that there is a "thin red line", but its location is simply indeterminate; it just to deny that there is a thin red line at all (Cf. Belnap and Green 1994 (in Belnap et al.: pp. 133-136) and Pooley 2013: p. 340. One further note: Cariani and Santorio say that their semantics presupposes that there is a unique actual course of history. If Will Excluded Middle is meant to follow from their semantics, which simply assumes that there is such a unique actual course of history, then I have no objection, for, as I note shortly, such an assumption plainly validates Will Excluded Middle. However, Cariani and Santorio-and
} 
this model of the open future to the former model. It is to assess the implications of the former model-which is, I believe, perfectly coherent.

But now we must consider the final model, viz., indeterminism with a privileged branch - a model that is often called "Ockhamism". The central idea here is this: though the world is (or certainly may be) perfectly causally indeterministic, there are nevertheless facts about how causally indeterministic processes will unfold. To be sure, these facts are (standardly) humanly unknowable, but the facts are there nevertheless, and they are perfectly determinate. ${ }^{8}$ To give expression to this model, various theorists have employed the idea of a privileged branch — a branch lit up, in Belnap and Green's (1994) terminology, with the "thin red line."9 Now, my claim is simple: it is the Ockhamist's model that is implicit in ordinary discourse. In ordinary discourse, we might grant that there are various ways things might go from here. Nevertheless, we take it for granted that we can, inter alia, reason about, talk about, and bet about the facts concerning how things will go from here. Of course, a philosopher may come along and challenge our assumption that there are such facts. But now we are in a philosophical context — and even if we grant this philosopher his or her point, we may soon find ourselves saying things that would seem to belie it. That is: we have lapsed back into the ordinary context.

Indeed, that the Ockhamist model is the model presupposed in ordinary discourse is made plausible by the observation that, as soon as we adopt one of the first two models, we find it immediately difficult to give a philosophical account of our future directed talk. ${ }^{10}$ Defenders of the first two models have certainly tried to address such worries, but the point is that they must be addressed. Ockhamism, however, generates no such difficulties. Instead, its difficulties are those of the metaphysician-namely, that it seemingly postulates a realm of fact (specified by "the thin red line") that outstrips what could be accounted for by current physical reality and the laws alone. ${ }^{11}$ And some feel that the existence of this realm of fact is objectionable. But the problems for the Ockhamist, then, are primarily metaphysical, not semantic.

And now we can note the following. The Ockhamist's model is a model on which the distinction between $\sim \mathbf{F n} p$ and $\mathbf{F n} \sim p$ is simply unimportant. Intuitively: if there are (determinate, fully complete, fully exhaustive) facts about how indeterministic processes will unfold, then if those facts don't have it that $p$ in $\mathrm{n}$ units of time, then they have it that $\sim p$ in $\mathrm{n}$ units of time. That is, we might say, just in the nature of "the facts". Slightly more carefully, in terms of the model, we might notice that it immediately vindicates the following pattern of reasoning:

It is not the case that: the privileged branch features $p$ in $n$ units of time. $(\sim$ Fn $p)$

\footnotetext{
Footnote 7 continued

certainly MacFarlane-appear to write as if scopelessness should hold no matter our model—or that it is, in some sense, a semantic constraint on the coherence of such models. And it is this that I wish to deny. The assumption that there is such a unique actual course of history is explanatorily prior to the intuition that will is scopeless.

${ }^{8}$ For a defense of Ockhamism thus understood, see Rosenkranz (2012).

${ }^{9}$ Cf. Malpass and Wawer (2012) and Wawer (2014).

${ }^{10}$ Cf. MacFarlane (2013: pp. 233-236), and Williams ms., on, e.g., the "assertion problem" and the "credence problem".

11 Cf. Belnap and Green (in Belnap et al 2001: p. 168).
} 
There is a privileged branch, which, for any $p$, either includes or excludes $p$ in $n$ units of time.

So, the privileged branch features $\sim p$ in $\mathrm{n}$ units of time. $(\mathbf{F n} \sim p)$

And there we have it: models with a privileged branch immediately validate the inference from $\sim \mathbf{F n} p$ to $\mathbf{F n} \sim p$. Further, such a model is, very plausibly, the model implicit in ordinary discourse. More particularly: I contend that, in ordinary discourse, the second premise is simply implicit and unspoken. This claim is, in some sense, simply a regulative principle undergirding ordinary thought and talk about the future. And this opens up the space to maintain the following: if a revisionist metaphysician denies the second premise, as does the open futurist, then that metaphysician will likewise have reason to deny the inference from $\sim \mathbf{F n} p$ to $\mathbf{F n} \sim p$. And if that metaphysician's model is itself coherent, then the inference will, indeed, by licensed by certain models of the future-but it is not one that should be licensed by semantic competence alone.

\section{Neg-raising: a primer}

Such is, in broad strokes, my account: it is difficult to hear a distinction between (13) and (14) because our linguistic sensibilities have been shaped against the background of an Ockhamist model of time-but once this model is denied, the two can be prized apart. This explanation is, perhaps, compelling enough for some already. But it can be made much more compelling yet. For the fundamental story I am invoking here-one on which a background model is making it so that what are in fact contraries seem like contradictories - is not some isolated semantic phenomenon that I must say is unique to this particular case. As Laurence Horn has written, this phenomenon is absolutely pervasive in language. It is tempting to let Horn-whose work on negation is as comprehensive as it is careful-explain the phenomenon in his own words. And so I will. Thus Horn:

As noted, contradictory terms (black/non-black, odd/even) exclude any middle term, an entity satisfying the range of the two opposed terms but falling under neither of them, a hat that is neither black nor not-black, an integer which is neither odd nor even. Contraries, by contrast, allow a middle: my shirt may be neither black nor white, my sister neither happy nor sad. Yet in certain remarkable circumstances the gap between the contraries narrows and even disappears, the middle effectively excluded or swallowed up. (2015: p. 246)

Horn (writing now with Wansing) continues:

In his dictum, "The essence of formal negation is to invest the contrary with the character of the contradictory", Bosanquet encapsulates the widespread tendency for formal contradictory (wide-scope) negation to be semantically or pragmatically strengthened to a contrary... The strengthening of a contradictory negation ... to a contrary typically instantiates the inference schema of disjunctive syllogism or modus tollendo ponens in (11):

(11) $\mathrm{A} \vee \mathrm{B} ; \sim \mathrm{A} ; \mathrm{B}$ 
Note: A and B are here contraries: both can be false, but not both true. However, given the first premise, $\mathrm{B}$, in effect, becomes the contradictory of $\mathrm{A}$; that is, if we have $\sim \mathrm{A}$, we have $\mathrm{B}$, and vice versa. Horn and Wansing continue:

While the key disjunctive premise is typically suppressed, the role of disjunctive syllogism can be detected in a variety of strengthening shifts in natural language where the disjunction in question is pragmatically presupposed in relevant contexts.

Among the illustrations of this pattern [is the] tendency for negation outside the scope of (certain) negated propositional attitude predicates (e.g. a does not believe that $p$ ) to be interpreted as associated with the embedded clause (e.g. $a$ believes that $\sim$ ); this is so-called "neg-raising".

When there are only two alternatives in a given context, as in the case of negraising (as stressed by Bartsch 1973; cf. Horn 1978, 1989, Chapter 5), the denial of one ... amounts to the assertion of the other. The relevant reasoning is an instance of the disjunctive syllogism pattern in (11), as seen in (12), where $F$ represents a propositional attitude and $a$ the subject of that attitude.

(12) $F(a, p) \vee F(a, \sim p)$ [the pragmatically assumed disjunction]

$\sim \underline{F}(\underline{a}, \underline{p})$ [the sentence explicitly uttered]

$F(a, \sim p)$ [the stronger negative proposition conveyed]

The key step is the pragmatically licensed disjunction of contraries [a believes that $p \vee$ a believes that $\sim p$ ]: if you assume I've made up my mind about the truth value of a given proposition $p$, rather than being ignorant or undecided about it, then you will infer that I believe either $p$ or $\sim p$, and my denial that I believe the former will lead you to conclude that I believe the latter. ${ }^{12}$

The key idea here is this: a believes that $p$ and $a$ believes that $\sim p$ are strictly speaking contraries: both could be false. However, if the disjunction of these contraries is presupposed in context, then $a$ does not believe that $p$ - what is strictly speaking [ $(a$ believes that $p$ )]—will tend to be interpreted as a believes that $\sim p$. That is, what is in fact semantically wide-scope negation gets interpreted as if it were associated with the "embedded clause". As Horn notes, however, neg-raising effects are not witnessed solely in cases of (certain) propositional attitudes. Commenting on Horn, Gajewski (2007: p. 292) summarizes:

\footnotetext{
12 Horn and Wansing (2015). Similar points can be found in Horn (2015) (and the classic Horn 1989). However, in the interest of simplicity, I have followed the more streamlined presentation of these points in Horn and Wansing (2015). Interestingly, elsewhere in their 2015, Horn and Wansing mention "future contingents" as a case in which one might reasonably claim that propositions often taken to contradictories are in fact contraries: "Other cases in which apparent contradictories can be seen as contraries, and thus immune from any application of LEM, are future contingents (There will be/will not be a sea battle tomorrow)." The authors do not, however, link this issue to the issue of neg-raising.
} 

A list of Neg-Raising predicates, arranged by semantic field (Horn 1989):
a. think, believe, suppose, imagine, expect, reckon, feel
b. seem, appear, look like, sound like, feel like
c. be probable, be likely, figure to
d. want, intend, choose, plan
e. be supposed to, ought, should, be desirable, advise, suggest

The central idea here is that in all of these cases, there is a semantic difference between the relevant wide-scope and narrow-scope readings (I don't think that p/I think that $\sim p$; I don't want to phi/I want to not phi; You're not supposed to phi/You're supposed to not-phi). However, in context, this distinction is often suppressed or otherwise masked - and this is because, in these contexts, we bring a certain model of the situation with us. In a context in which I am assuming that you're not simply indifferent (that you aren't indifferent is part of my background model of the situation), when you say that you don't want to come to the party, I hear this as an assertion that you want to not come. Indeed, it is extremely difficult to hear I don't want to come as anything but this stronger assertion-or, perhaps, it is difficult to imagine that there even is a stronger assertion available (He said he doesn't want to come! Quit asking him.). At the same time, on reflection, we are capable of seeing that it is possible (even if, in context, probably unkind) for someone truly to say I don't want to come, although that person doesn't want to not come-because, at the moment, that person is completely indifferent. That is, on reflection, we can grant that does not want to come does not semantically entail wants not to come. It does so only holding fixed our assumed model of the situation, viz. that you aren't indifferent. If, indeed, you aren't indifferent, then that you don't want to come does imply that you want not to. But once this model is relinquished, a scope distinction becomes salient that was otherwise practically irrelevant.

And this is plainly deeply similar to what I wish to say about will and will not. Indeed, my claim is that we may plausibly add will to the list of neg-raising predicates above. ${ }^{13}$ In this case, the relevant inference pattern identified by Horn, I contend, goes as follows:

\footnotetext{
13 In this paper, I defend the claim that will is a "neg-raiser". However, some might have a conception of "neg-raising" that prohibits will from being a neg-raiser from the start. Roughly, on a certain syntactic approach to neg-raising (cf. Collins and Postal 2014), neg-raising is essentially a bi-clausal operation (in which the negation is "raised" from the lower clause). An anonymous referee for this journal thus notes that if neg-raising is essentially such an operation, if will is a modal, will cannot be a neg-raiser, since a modal is in the same clause as the main verb it governs. However, some in the literature have employed a more permissive approach to the terminology of "neg-raising"; as just noted by Gajewski, for instance, Horn (1978: p. 198) claims that the deontic modal should is a neg-raiser, on grounds that I don't think he should go to the party strongly conveys I think he should not go to the party. In this paper, I thus assume a conception of "neg-raising" that does not prohibit will from being a "neg-raiser" on terminological grounds alone; in other words, I assume a conception on which should is appropriately called a "neg-raiser" (and thus, in principle, a conception on which will can be a neg-raiser). For more on these issues, see Collins and Postal (2017), which clarifies the relationship between the syntactic theory of neg-raising developed in their 2014 and the pragmatic/excluded middle approach to which I appeal in this paper. Collins and Postal (2014) reserve the label "Classical Neg-Raising" (CNR) for neg-raising in the more narrow sense just noted; I thus assume that not all neg-raising is classical neg-raising.

Incidentally, the comparison with should is instructive, although a full discussion of this issue lies outside the scope of the present paper. (Cf. Horn's [1978: p. 200] discussion of St. Anselm on the Latin ducere.) "Trump should be impeached or Trump should not be impeached" certainly sounds initially like
} 
(1) There is a privileged branch, which, for any $p$, either includes or excludes $p$ in $\mathrm{n}$ units of time. (Implicit, unspoken assumption)

(2) $\mathbf{F n} p \vee \mathbf{F n} \sim p$. (Trivial consequence of (1) —and establishment of semantic contraries) (e.g. Trump will be impeached in an hour or Trump will not be impeached in an hour)

(3) $\sim \mathbf{F n} p$ (The proposition considered or uttered) ("It is not the case that Trump will be impeached in an hour"/"I deny [assert that it is false] that Trump will be impeached in an hour")

(4) Fn $\sim p$ (The proposition communicated or expressed) ("Trump will not be impeached in an hour")

The situation, then, is this. We can see the distinction between the original items in (13) and (14) as continuous with a wide range of linguistic data in which distinctions of scope are suppressed or masked by the implicit models we bring to the relevant contexts. At the same time, the difference between the case of will and will not and the cases listed above is perhaps obvious. For instance, as explained, in context, we may bring with us a supposition that Jones has thought about the matter and formed an opinion one way or the other; when Jones thus says that he doesn't think that $p$, we interpret this to mean that he thinks that $\sim p$. But it is, for most of us, relatively easy to forego or cancel this assumption; all of us are familiar with the situation of withholding belief (or being agnostic). Thus, when such an option is made salient, we are able to consider Jones does not think that $p$ as true and Jones thinks that $\sim p$ as false. He's an agnostic on this matter, so the inference that usually holds good does not hold good.

In this case, then, the situation that makes salient the difference in scope is relatively familiar and benign. But this plainly is not the case for will and will not. Indeed, the purported situation that would make salient the difference in scope is a situation that would only be insisted on by a philosopher. Only a philosopher-a philosopher!- would think to question the inference from (3) to (4), because only a philosopher would have cause to consider and reject (1) (and thereby (2)). Only philosophers (broadly conceived) are concerned with "models of the undetermined future", and only philosophers would contend that, as far as we know, indeterminism with no privileged branch is the correct such model. Ordinary persons in ordinary life may pause to say Well, wait-maybe Jones hasn't considered the matter, so, sure, he doesn't think that $p$, but maybe he also doesn't think that $\sim$. But only a philosopher would wish to pause to say, Well, wait-maybe there are no facts about undetermined aspects of the future, so, sure, it isn't yet the case that it will happen an hour from now, but maybe it also isn't yet the case that it won't happen an hour from now. This, then, plausibly explains why will has not (to my knowledge) yet appeared on any list of neg-raising predicates. Semanticists and linguists concerned with the theory of neg-raising are plainly not going to be concerned with cases that appear, if at all, only

\section{Footnote 13 continued}

an instance of $(p \vee \sim p)$, although, on reflection, we may be prepared to grant that it isn't; for someone on the fence, it is not the case that he should be impeached, and not the case that he should not be impeached. So similarly, when reality is "on the fence" concerning Trump's impeachment tomorrow, I say, it is not the case that he will be impeached tomorrow, and not the case that he will not be impeached tomorrow. It is open. I am grateful to an anonymous referee for helpful discussion of these points. 
in the context of an explicit rejection of a metaphysical theory of time. (Their work is already difficult enough. $)^{14}$

And so the difference is this. The situation, I contend, that masks the relevant scope difference in the case of will is thoroughgoing and metaphysically entrenched. However, the claim that the scope differences are there is deeply theoretically motivated. We just need some priming to bring them out. To such priming I now turn.

\section{Perfect anticipation: variations on a Priorean theme}

Consider one predicate from Gajewski's list: expect-or, in other words, anticipate. This is an especially interesting case for our purposes, since this is an attitude that is itself future directed. Now, note that anticipate is neg-raising in the standard way: Jones doesn't anticipate rain strongly implicates-though does not semantically entail-Jones anticipates no rain [viz., an absence of rain]. ${ }^{15}$ And this is, I think, deeply suggestive: in the same way, I contend, it is not the case that it will be raining in an hour strongly implicates - but does not semantically entail-It will be in an hour that it is not raining. What is merely suggestive could be turned into an argument, however, if we could simply identify Jones anticipates rain in an hour with It will rain in an hour. Jones, however, is not God.

But then: what about God? What about, to use a title of A.N. Prior's, "The Formalities of Omniscience" (Prior 1962)? ${ }^{16}$ Intuitively, in the case of God (minimally defined as an omniscient being) we could simply help ourselves to the given identification. After all, assuming bivalence (which the current theory can happily assume), for an omniscient being, the following should hold:

If God anticipates a sea battle in $\mathrm{n}$ units time, there will be a sea battle in $\mathrm{n}$ units time, and if there will be a sea battle in $n$ units time, then God anticipates a sea battle in n units time. (For all $p:$ Fnp iff Antnp)

\footnotetext{
14 An anonymous referee for this journal observes that, assuming that think is a neg-raiser, the first pair below seems extremely close, whereas the second pair (in which will plausibly conveys intention, and not mere futurity) seem less close:
}

I think it won't rain.

I don't think it will rain. [very close if think is a neg-raiser here]

I think I won't take the job. [I've pretty much made up my mind to decline it]

I don't think I will take the job. [It's less of a settled decision]

In other words: when will conveys intention, it is less obvious-without appeal to open futurist metaphysics! - that we can unproblematically move the negation in I don't think I will inside the scope of the will.

15 Again, I assume a broad conception of "neg-raising" on which I don't anticipate rain can constitute an instance of neg-raising, even though there is here no lower clause from which to extract the negation. See note 13 above.

16 For more on these themes, and how they pose problems for supervaluationist and relativist treatments of future contingents, see Todd and Rabern ms. 
But now consider the following:

G1. God anticipates $p$ in units time.

$\mathrm{G} 2$. God does not anticipate $p$ in $\mathrm{n}$ units time.

G3. God anticipates $\sim p$ in $\mathrm{n}$ units time.

We can now ask: does G2 entail G3?

Certainly many have thought that it does; Ockham himself (after whom Ockhamism) would certainly contend that it does. That is, on the standard, classical picture of divine omniscience, defended at length by Ockham, if God does not anticipate a sea-battle tomorrow, that is going to be because God anticipates the absence of a sea-battle tomorrow. And this is plainly because, for Ockham, God, being God, somehow has access to the location of the "thin red line" - that is, the facts about how indeterministic processes shall unfold. ${ }^{17}$ Thus, for a theorist like Ockham, we might say the following: For God, absence of an anticipation is always anticipation of an absence. If, in God, there is no anticipation of $p$ in $\mathrm{n}$ units time, and so G2 is true, this is going to entail that, in God, there is an anticipation of $\sim p$ in $\mathrm{n}$ units time. Thus, for a theorist like Ockham, if God does not now anticipate a sea-battle tomorrow, then you can rest easy: this by itself implies that there is going to be no sea-battle tomorrow.

But now the crucial point: though G2 may indeed entail G3, it is obvious that this entailment is substantive, not semantic. That is, it is obvious that G2 cannot simply be rewritten as G3 - as if G3 carries with it no new semantic content over and above $\mathrm{G} 2$. The argument that $\mathrm{G} 2$ does indeed entail G3 takes us well beyond mere semantic competence. Indeed, my own picture of the open future might be perfectly captured in the following slogan:

Even for an omniscient being, absence of anticipation does not always imply anticipation of absence.

More particularly, we stipulate that God is perfectly omniscient regarding the future: For all $p, \mathbf{F n} p$ iff Antnp. We then ask God:

Us: Do you anticipate a sea-battle tomorrow?

God: No. ( Antn $p)$

Us: Do you anticipate there not being a sea-battle tomorrow?

God: No. ( Antn $\sim p)$

Us: So you're saying the future is open?

God: Precisely. I don't anticipate a sea-battle, but then again, I don't anticipate the absence of a sea-battle. At this stage, I have no anticipation either way.

If the future is genuinely open, in the sense I wish to defend, then from the fact that an omniscient being does not have an anticipation of it becoming the case that $p$ in $n$ units time, it simply would not follow that that being has an anticipation of its becoming the case that $\sim p$ in n units time. That is, for some $p$, it would be false that Antn $p$, and false that Antn $\sim p$. And so similarly for the propositions to which these seem equivalent: Fn $p$ and $\mathbf{F n} \sim p$.

\footnotetext{
17 Hence Ockham's famous admission: "It is impossible to express clearly the manner in which God knows future contingents." (Ockham in Adams and Kretzmann 1969: p. 50).
} 
In sum, the argument is this: G1-G3 seem perfectly equivalent to W1-W3.

G1. God anticipates $p$ in $\mathrm{n}$ units time.

$\mathrm{G} 2$. God does not anticipate $p$ in $\mathrm{n}$ units time.

G3. God anticipates $\sim p$ in $n$ units time.

W1. It will be that $p$ in $\mathrm{n}$ units time.

$\mathrm{W} 2$. It is not the case that it will be that $p$ in $\mathrm{n}$ units time.

$\mathrm{W} 3$. It will be that $\sim p$ in $\mathrm{n}$ units time.

And if these are equivalent, then if G2 does not semantically entail G3 (and it doesn't), then W2 should not semantically entail W3. G1 and G3 are semantic contraries. At any rate, if both can't be false, this is one's theory talking, not one's semantic competence. So similarly for W1 and W3.

\section{Against scopelessness: natural language}

But now we must see how a denial of scopelessness may manifest itself in natural language. I maintain, crucially, that we can perfectly well understand such a denial in ordinary speech, once it becomes clear that we are in something like a "philosophical" context. Suppose James is a recalcitrant (and slightly pedantic) open futurist. He believes, that is, in the metaphysical model of time we have called indeterminism with no privileged branch. Consider:

Karen: There will be rain in one hour from now.

James: Well, strictly speaking, I deny that.

Karen: So you're saying there won't be rain in an hour. But have you...

James: Well, wait. I deny that too.

Karen [puzzled]: ... you're saying that it isn't the case that there will be rain in an hour, and also not the case that there won't be rain in an hour?

James: Right. The future is open! When I denied that there will be rain in an hour, I didn't mean to affirm that, in an hour, it will be that there is no rain. I think there's just no fact of the matter yet concerning the status of rain in an hour. There may be rain in an hour, and may not be rain in an hour-but I deny that there will be rain in an hour, and that there will not be rain in an hour. Again: I think there is just no fact stating that there "will" or instead "will not" be rain in an hour; so I deny both. It is open!

My claim here is not-and needn't be - that James' overall position here is plausible. My claim, instead, is that James does not seem to be contradicting himself, and that this is inconsistent with scopelessness. Scopelessness requires, that is, that there is no difference in meaning between $\sim \mathbf{F n} p$ and $\mathbf{F n} \sim p$. If this were so, however, then in maintaining that $\sim \mathbf{F n} p$, James would thereby be maintaining that $\mathbf{F n} \sim p$-and therefore we would not be able to understand the contrast James is here trying to bring out. We 
would instead be convinced that he was contradicting himself. However, on suitable reflection, we do understand that contrast, and James does not seem to be contradicting himself. He instead seems to have a theory of the future that he insists on inflicting upon Karen. (And that is fine: I am a philosopher with a theory that I insist on inflicting, not upon members of the public, but upon other philosophers.) The result is simple: as a semantic thesis about meaning, scopelessness is implausible.

I appreciate that many readers may still be left with the impression that there is something, well, fishy about James' speech. And this I am certainly happy to grant: James is certainly saying something that sounds unnatural, and, I am willing to grant, even a bit stilted. But this is unsurprising. James' position is explicitly motivated by, and modeled on, a revisionary metaphysics; precisely James' contention is that the model of the future implicit in ordinary discourse is mistaken. Accordingly, it shouldn't be surprising that his own position is not easily and naturally stated within such discourse. (Ordinary language needn't have evolved in order to match the true metaphysics.) Consequently, when philosophically assessing James' speech, first we must look at the metaphysical model of the future (indeterminism with no privileged branch) that allegedly motivates it, and we must decide whether that model is coherent. If we decide that it is (and, for what it is worth, it does seem that it is), then we must see whether what James is saying is a plausible consequence of that model-or is understandable in light of that model. And once more, this seems to be the case. On this model of the undetermined future, we should grant, just because it is not the case that it will be in $\mathrm{n}$ units of time that $p$, it shouldn't follow that it will be in $\mathrm{n}$ units of time that $\sim p$. And this is what matters.

\section{Some comparisons}

At this stage, it is worth pausing to remark on precisely how (in Cariani and Santorio's words) "remarkable" scopelessness really would be. As they note, that will is scopeless would be a unique future of will amongst other modals: to my knowledge, there are no other modals M-of whatever "flavor"-such that there is no truth-conditional difference between $\sim \mathbf{M} p$ and $\mathbf{M} \sim p .{ }^{18}$ Consider:

(i) Necessity. $\sim($ Necessarily $p$ ) does not mean Necessarily $\sim p$.

\footnotetext{
18 What counts as a "modal" in this context? It is difficult to say (cf. Pullum and Huddleston 2002: p. 172.) At any rate, Cariani and Santorio contrast will with must and might, which, they say, are modals that do not commute freely with negation-and those I have listed in what follows seem standard. (I set aside the claim that negation itself is a modal [for discussion, see Berto and Restall forthcoming]; negation would seem to commute freely with itself.)

A further note: we can observe that there are indeed modals-possibility modals-in which $\sim \mathbf{M} p$ does imply $\mathbf{M} \sim p$, although not the other way around, e.g. metaphysical possibility. Under standard assumptions, $\sim$ Possibly $p$ implies Possibly $\sim p$, though not vice versa. "Possibly" is thus not "scopeless", although $\sim$ Possibly $p$ does imply Possibly $\sim p$. (Similar claims can be made concerning epistemic possibility and deontic permissibility.)

What is thus (minimally) required for the claim that $\sim \mathbf{F n} p$ does not imply $\mathbf{F n} \sim p$ is the claim that will is stronger than a possibility modal. And, indeed, this is plausible: intuitively, to say that something will happen is to say something stronger than that it is possible for it to happen. Intuitively, in terms of modal strength, will lays between may and must: it is stronger than it may happen and weaker than (but of course does not rule out) it must happen.
} 
'Necessarily $p \vee$ Necessarily $\sim p$ ' eliminates contingency.

(ii) Must (epistemic). (According to $\mathrm{S}$, it must be that $p$ ) does not mean According to $\mathrm{S}$, it must be that $\sim p$.

'According to $\mathrm{S}$, it must be that $p \vee$ According to $\mathrm{S}$, it must be that $\sim p$ ' eliminates uncertainty.

(iii) Obligation. $\sim(\mathrm{S}$ is obligated to see to it that $p)$ does not mean $\mathrm{S}$ is obligated to see to it that $\sim p$.

' $\mathrm{S}$ is obligated to see to it that $p \vee \mathrm{S}$ is obligated to see to it that $\sim p$ ' eliminates mere permission.

(iv) Belief. $\sim(\mathrm{S}$ believes that $p$ ) does not mean $\mathrm{S}$ believes that $\sim p$.

' $\mathrm{S}$ believes that $p \vee \mathrm{S}$ believes that $\sim p$ ' eliminates agnosticism.

(v) Intention. $\sim(\mathrm{S}$ intends to bring it about that $p$ ) does not mean $\mathrm{S}$ intends to bring it about that $\sim p$.

' $\mathrm{S}$ intends to bring it about that $\mathrm{p} \vee \mathrm{S}$ intends to bring it about that $\sim p$ ' eliminates indecision.

My point here is not that since these operators are not scopeless, will cannot be scopeless. Perhaps there is an important disanalogy between will and these other operators. My point, instead, is twofold. First, it is burden-shifting: proponents of scopelessness must explain what this disanalogy comes to. Second, and more importantly, it is illustrative: if it is claimed, from the outset, as a semantic "constraint" on our theorizing, that the operators at issue in (i)-(v) are scopeless, then, from the outset, we seemingly eliminate as possibilities contingency, uncertainty, mere permission, agnosticism, and indecision. And the argument of this paper is that if is it similarly insisted that will is scopeless, then we eliminate, from the outset, what I would like to call openness. My theory is that openness stands to will as mere permission and contingency stand to obligation and necessity.

We thus have a choice: we can defend the claim that will is unique amongst modals in being scopeless with respect to negation. Alternatively, we can maintain that will is unique amongst modals in having standard scope interactions with negation, but these interactions being systematically suppressed in ordinary thought and talk by our implicit assumptions about its unique subject matter - namely, the future. The former approach must see will as semantically discontinuous with other modals. The latter approach instead can see will as perfectly semantically continuous with other such

\footnotetext{
Footnote 18 continued

Incidentally, we can connect this claim about will with a theme from Horn on the nature of neg-raising, although a full discussion of these issues must lie outside the scope of the present paper. In his 1975, Horn considers as a necessary condition on neg-raising something he calls "midscalar generalization". (For discussion, see Gajewski 2005: pp. 86-90.) Roughly, the idea is that expressions in the same semantic field can be ordered in terms of logical strength, e.g., some, many, most, all —and that, in order to be a neg-raiser, the expression must be somewhere in the middle. (For more on this theme, see Pullum and Huddleston's (2002: pp. 838-843) discussion of "increased specificity of negation" in terms of "medium strength modality".) My point here is not that neg-raisers must be "medium strength" in the requisite way; my point is instead that, if it is claimed that they must be, then one could plausibly contend that will is "medium strength".
} 
modals - and, indeed, can see the suppression of the relevant scope distinctions as perfectly continuous with a whole range of distinct semantic data (identified in the neg-raising literature) in which we can observe precisely the phenomenon I have here identified. The latter option sees deep continuity where the former sees discontinuity. The latter option, I contend, is preferable.

\section{Some objections}

Here is the first.

You just maintained that, if we insist that will is scopeless, then from the outset, we eliminate "openness". But this is false. Suppose, as you grant, that "openness" is the state of affairs that obtains with respect to $p$ (in n units of time) when it is not true that $\mathbf{F n} p$ and not true that $\mathbf{F n} \sim p$. Well, we can maintain scopelessness and Will Excluded Middle ( $\mathbf{F n} p \vee \mathbf{F n} \sim p$ ) consistently with openness thus defined: we can say that neither such disjunct is true, but that the disjunction is true.

Granted. Strictly speaking, we do not eliminate openness thus-conceived: we simply make its expression difficult to understand. Consider, after all, the following parody of the above speech:

You just maintained that if we insist that necessity is scopeless, then, from the outset, we eliminate contingency. But this is false. Suppose, as you may grant, that contingency is the state of affairs that obtains with respect to $p$ when it is not true that Necessarily $p$ and not true that Necessarily $\sim p$. Well, we can maintain 'Necessarily $p \vee$ Necessarily $\sim p$ ' consistently with contingency thus defined: we can say that neither such disjunct is true, but that the disjunction is true.

And parallel claims may be made for the other given operators in (ii)-(v). But the response to any such claim is clear. We simply have no need to say that contingency is the state of affairs that obtains with respect to $p$ when, roughly, it is indeterminate whether it is necessary that $p$ or instead necessary that $\sim p$. We have the theoretically far more satisfactory option of saying that it is the state of affairs that obtains when both such claims are false - and thus when the given disjunction is false. And so similarly for openness. Philosophers attracted to the "open future" have felt the need to invoke the mysterious sort of "openness" at issue in the first speech precisely because they have felt the need to respect (something like) scopelessness. Once scopelessness is denied, however, then we are in position to say that openness is no more mysterious than contingency, uncertainty, mere permission, agnosticism, and indecision-intuitively, all of which obtain when both of the relevant claims are false. Once again, we have continuity where other approaches must see discontinuity.

The second objection is related to the first:

Well, those philosophers were on to something. For your core idea, developed at length above, is that we are inclined to accept scopelessness-and Will Excluded Middle-only because we bring with us a certain model of the future, viz., a model on which there is a "thin red line" or "privileged branch", the existence 
of which makes the distinction between $\sim \mathbf{F n} p$ and $\mathbf{F n} \sim p$ practically irrelevant. But this is false. For even if there is no thin red line, Will Excluded Middle still seems true. That is, even if I am explicitly taking into account that there is no privileged branch, "Trump will be impeached in an hour or Trump will not be impeached in an hour" still seems true-even if, as you say, Trump is impeached in an hour on some such branches, and not on others, and there is nothing at all to break the tie. And so your claim that the purported scope distinctions are being masked by this assumption is false: for the intuition that there are no such distinctions survives the explicit denial of that assumption.

My response to such an objection is simple: No it doesn't. It does not still seem that 'Trump will be impeached in an hour or Trump will not be impeached in an hour' is true, once we have before us a model on which Trump is impeached in an hour on some branches and not on others, and with nothing at all to break the tie. For consider the claim that Trump will be impeached in an hour. We check: there is nothing in the model to make such a claim true; and if a claim isn't true, it is false. So that claim is false. And consider the claim that Trump will not be impeached in an hour. We check: there is nothing in the model to make such a claim true; and if a claim isn't true, it is false. So that claim is false. But the disjunction of two falsehoods is false. Surprise! 'Trump will be impeached in an hour or Trump will not be impeached in an hour' is false. (I did promise an error-theory.) So what the objector says still seems true does not still seem true.

But the objector may wish to interject:

But you are simply assuming bivalence. If we assume bivalence, then the given disjuncts are going to turn out false, and the disjunction false. But you cannot assume bivalence in this context.

Such an objection shows - or would show — that we have lost sight of the longstanding historical discussion of the problem of future contingents. Traditionally, the problem for the open futurist has not been that she has simply assumed bivalence-indeed, the problem has been that she cannot assume bivalence. The problem has been, in other words, that if we assume bivalence, the open futurist's position ends in contradiction (or some other similar disaster). ${ }^{19}$ It cannot be a problem for my view that I am assuming bivalence: what must be shown is that something absurd follows from such an assumption, together with the denial of the claim that either such disjunct is true. And this is what I claim has not been shown.

However, the objector may wish to say more:

Let me back up. The problem is how you are proceeding when evaluating 'Trump will be impeached in an hour or Trump will not be impeached in an hour'. You are simply going to the model, checking the first disjunct against that model, then returning to the model, and checking the second disjunct against that model—and

\footnotetext{
19 In particular, the traditional problem is that, if we say that both such disjuncts are false, we will have to say that the given disjunction is false-but the disjunction is an instance of LEM, and so we must deny LEM. Response: as I argued above, the disjunction is not an instance of LEM!
} 
you are then employing the standard semantics for disjunction to return the claim that the given disjunct is false. But you are hereby missing the intuition, which is that looking directly at the disjunction as a whole, the disjunction seems true-and, again, still seems true, even though we recognize that there is nothing in the model to support either disjunct.

But the problem here is twofold. First, I seem to stand accused of employing the otherwise perfectly standard way of evaluating the truth of a disjunction to evaluate the truth of this particular disjunction. This is not, I believe, a compelling objection. Second, the problem once more comes in the final line: why should we still maintain that the disjunction seems true, once we recognize that the model supports neither disjunct? Why not instead conclude that a claim that initially seemed true is not in fact true, given that model? The open future has surprises; this much, however, is not surprising.

What this sort of objector likely has in mind, however, is something like this.

But look: no matter how things go, Trump gets impeached in an hour, or does not get impeached in an hour; accordingly, he will get impeached in an hour, or he won't get impeached in an hour. As we might say: it will be one or the other! How can we deny that it will be one or the other, when those are the only two options? Accordingly, even when we explicitly recognize that there is nothing to break the tie, and so it is not true that it will be one, and not true that it will be the other, we still must grant that it will be one or the other.

And it is here that we encounter, perhaps, the crux of the issue-and it is here, I contend, that we must be extremely careful. For how should we interpret the crucial claim here, viz., that it will be one or other? How should that intuition be made more precise?

Prima facie, it seems that we should write 'It will be one or the other' as follows: 'Fn $(p \vee \sim p)$ '. And here we encounter the beginnings of what I believe to be a plausible error-theory for why 'Will Excluded Middle' '(Fn $p \vee \mathbf{F n} \sim p)$ ' can seem so plausible, even if we grant the openness of the future (indeterminism plus no privileged branch). And that is that we are mistaking a true claim, viz. ' $F n(p \vee \sim p)$ ' with a false claim, viz. ' $(\mathbf{F n} p \vee \mathbf{F n} \sim p)$ '. The former is not a future contingent, but a future necessity ( $(p \vee \sim p)$ holds on all branches). The latter, however, is the disjunction of two future contingents. The former says, in short, that it will continue to be in $n$ units of time that LEM holds - and surely it must, and so surely it will. The latter, however, says not that LEM will hold in $\mathrm{n}$ units of time, but that, one the one hand, it will be that $p$ in $\mathrm{n}$ units time, or, on the other, it will be that $\sim p$ in $\mathrm{n}$ units time. And this is to say something much stronger than the former claim. On reflection, however, I believe that, often, when we try to justify ' $(\mathbf{F n} p \vee \mathbf{F n} \sim p)$, we lapse into what is in fact not a justification of that claim, but instead a justification of ' $\mathbf{F n}(p \vee \sim p)$ ' ${ }^{20}$ Consider, after

${ }^{20}$ Cf. Williamson (1988: p. 412) for a similar point as concerns, not will excluded middle, but the much more widely discussed conditional excluded middle (CEM). The denier of CEM must defend a distinction between (If it had been that $p$, it would have been that $q$ ) and (If it had been that $p$, it would have been that $\sim q$ ). For a treatment of the parallels between CEM and WEM, and an extension of the neg-raising 
all, the objector's final line: even though it is not true that it will be one, and not true that will be the other, we still must grant that it will be one or the other. And surely that is right: it will be one or the other. No matter which future we choose, that future has it (in $\mathrm{n}$ units of time) that $p$ or has it that $\sim p$-accordingly, it will be in $\mathrm{n}$ units of time that $p \vee \sim p$. That, I believe, is the intuition that must be respected. But that is an intuition my account can happily accommodate. And once again, a comparison with the operators at issue in (i)—(v) is instructive. In these cases, ' $\mathbf{M}(p \vee \sim p)$ ' does not imply ' $\mathbf{M} p \vee \mathbf{M} \sim p$ '. Similarly, I claim, 'Fn $(p \vee \sim p)$ ' does not imply '(Fn $p \vee \mathbf{F n} \sim p)$ '. Once again, my account sees continuity where others must see discontinuity.

\section{Conclusion}

It is worth summing up the picture that results from the above discussion. In sum, on the view I favor, when we have $p$ in $n$ units of time on some but not all branches, and no 'thin red line', we have the following:

$\mathbf{F n} p \vee \sim \mathbf{F n} p-$ true.

This is a classical instance of LEM, and, in this scenario, the first disjunct is false, and the second disjunct is true. After all, we have nothing in the model to make Fn $p$ true (we have no privileged branch on which $p$ in $\mathrm{n}$ units time, and we do not have $p$ in $\mathrm{n}$ units time on all the branches)_and if Fnp is not true, it is false: so we have $\sim \mathbf{F n} p$. And so the disjunction is true. Now consider:

$\mathbf{F n} p \vee \mathbf{F n} \sim p$-false.

This is not an instance of LEM, and, in view of the reasoning just given, in this scenario, both disjuncts are false. Will Excluded Middle is denied.

$$
\mathbf{F n}(p \vee \sim p) \text {-true. }
$$

Even if $p$ in $\mathrm{n}$ units time isn't on all branches, $p \vee \sim p$ certainly is, and even if there is no 'privileged branch', and so no privileged branch on which $q$, if $q$ is nevertheless on all branches in n units time, this should suffice for the truth of $\mathbf{F n} q$.

This picture is plainly simple and it is plainly classical. I do not hereby claim that this is a decisive advantage for this view-but I do contend that it is a view that deserves serious consideration by philosophers working on these topics. The primary obstacle to this view has been the suspicion that its crucial resource-the distinction in scope between $\sim \mathbf{F n} p$ and $\mathbf{F n} \sim p$-is, in MacFarlane's words, simply "missing". Above, however, I have argued that this distinction is not missing, but is being masked by our implicit assumptions about the future-an argument that gains substantial traction once we see will as continuous with other so-called "neg-raisers". Such a view can allow us to see to will as semantically continuous with the modals at issue in (i)-(v) above - and thus as having meaningful scope interactions with negation - and can see openness on analogy with (inter alia) contingency and mere permission. To be sure,

Footnote 20 continued

explanation provided above to the case of would, see Todd ms. I deny CEM, and claim that if CEM is not a semantic truth — and many have thought that it is not—-then neither is WEM a semantic truth. 
whether these scope interactions are important or practically relevant is a question beyond the scope of this paper-for this question is, as I have argued, inevitably and finally a question for the metaphysician. ${ }^{21}$

Open Access This article is distributed under the terms of the Creative Commons Attribution 4.0 International License (http://creativecommons.org/licenses/by/4.0/), which permits unrestricted use, distribution, and reproduction in any medium, provided you give appropriate credit to the original author(s) and the source, provide a link to the Creative Commons license, and indicate if changes were made.

\section{References}

Adams, M. M., \& Kretzmann, N. (1969). William Ockham: Predestination, God's Foreknowledge, and Future Contingents. Translated with an introduction and notes. New York: Century Philosophy Sourcebooks, Appleton-Century-Crofts.

Barnes, E., \& Cameron, R. (2009). The open future: bivalence, determinism, and ontology. Philosophical Studies, 146, 291-309.

Belnap, N., \& Green, M. (1994). Indeterminism and the Thin Red Line. Philosophical Perspectives, 8, 365-388.

Belnap, N., Perloff, M., \& Xu, M. (2001). Facing the future: Agents and choices in our indeterministic world. Oxford: Oxford University Press.

Berto, F., \& Restall, G. Forthcoming. Negation on the Australian Plan. Journal of Philosophical Logic.

Bourne, C. (2006). A future for presentism. Oxford: OUP.

Cariani, F., \& Santorio, P. (2017). Will done better: Selection semantics, future credence, and indeterminacy. Mind, 127, 129-165. https://doi.org/10.1093/mind/fzw004.

Collins, C., \& Postal P. 2017. Disentangling two distinct notions of NEG raising. Posted on Lingbuzz, https://ling.auf.net/lingbuzz/003595.

Collins, C., \& Postal, P. (2014). Classical NEG raising: An essay on the syntax of negation. Cambridge, MA: MIT Press.

Gajewski, J. 2005. Neg-raising Polarity and Presupposition. Dissertation: MIT.

Gajewski, J. (2007). Neg-raising and polarity. Linguistics and Philosophy, 30, 289-328.

Hartshorne, C. (1965). The Meaning of 'Is Going to Be'. Mind, 74, 46-58.

Hess, E. (2017). The open future square of opposition: A defense. Sophia, 56, 573-587.

Horn, L. (1975). Neg-raising predicates: Toward an explanation. CLS, 11, 279-294.

Horn, L. (1978). Remarks on neg-raising. In P. Cole (Ed.), Syntax and Semantics 9: Pragmatics (pp. 129-220). New York: Academic Press.

Horn, L. (1989). A natural history of negation. Chicago: The University of Chicago Press.

Horn, L. (2015). On the contrary: Disjunctive syllogism and pragmatic strengthening. In A. Koslow \& A. Buchsbaum (Eds.), The road to universal logic. Springer: Studies in Universal Logic.

Horn, L. R., \& Wansing, H. (2015). Negation, The Stanford Encyclopedia of Philosophy (Spring 2017 Edition), Edward N. Zalta (ed.). https://plato.stanford.edu/archives/spr2017/entries/negation/

Kodaj, D. (2013). Open future and modal anti-realism. Philosophical Studies, 168, 417-438.

Lukasiewicz, J. (1920). On three-valued logic. In S. McCall (Ed.), Polish logic, 1920-1939. Oxford: Oxford University Press.

MacFarlane, J. (2013). Assessment sensitivity: Relative truth and its applications. Oxford: Oxford University Press.

Malpass, A., \& Wawer, J. (2012). A future for the thin red line. Synthese, 188(1), 117-142.

Pooley, O. (2013). Relativity, the open future, and the passage of time. Proceedings of the Aristotelian Society, 113, 321-363.

Prior, A. N. (1957). Time and modality. Oxford: OUP.

Prior, A. N. (1962). The formalities of omniscience. Philosophy, 37, 114-129.

${ }^{21}$ For helpful comments on previous drafts of this paper and/or helpful discussion, I wish to thank two anonymous referees for this journal, David Plunkett, Paolo Santorio, Fabrizio Cariani, Daniel Rothschild, Jon Gajewski, and most of all my colleagues at the University of Edinburgh, Geoff Pullum, Wolfgang Schwarz, Bryan Pickel, Anders Schoubye, and especially Brian Rabern. 
Prior, A. N. (1967). Past, present, and future. Oxford: OUP.

Pullum, G., \& Huddleston, R. (2002). The Cambridge Grammar of the English Language. Cambridge: Cambridge University Press.

Rhoda, A. (2007). The philosophical case for open theism. Philosophia, 35, 301-311.

Rosenkranz, S. (2012). In defence of ockhamism. Philosophia, 40, 617-631.

Thomason, R. (1970). Indeterminist Time and Truth Value Gaps. Theoria, 36, 264-281.

Todd, P. (2016). Future contingents are all false! On behalf of a Russellian open future. Mind, 125(499), $775-798$.

Todd, P. The will/would connection. (Unpublished ms).

Todd, P., \& Rabern., B. Future contingents and the logic of temporal omniscience. (Unpublished ms).

Wawer, J. (2014). The truth about the future. Erkenntnis, 79, 365-401.

Williamson, T. (1988). Bivalence and subjunctive conditionals. Synthese, 75, 405-421.

Williams, J.R.G. Aristotelian indeterminacy and the open future. (Unpublished ms).

\section{Affiliations}

\section{Patrick Todd ${ }^{1}$}

$凶 \quad$ Patrick Todd

Pat.c.todd@gmail.com

1 The University of Edinbugh, Dugald Stewart Building, 3 Charles Street, Edinburgh EH8 9AD, UK 